\title{
Interleukin 1 and interleukin $1 \beta$ converting enzyme (caspase 1) expression in the human colonic epithelial barrier. Caspase 1 downregulation in colon cancer
}

\begin{abstract}
A Jarry, G Vallette, E Cassagnau, A Moreau, C Bou-Hanna, P Lemarre, E Letessier,
\end{abstract} J-C Le Neel, J-P Galmiche, C L Laboisse

\begin{abstract}
Background-Interleukin (IL) $1 \beta$ converting enzyme (now known as caspase 1) is able to process pro-IL-1 $\beta$ into its active form and is involved in proapoptotic signalling.

Aims-To characterise IL-1 and caspase 1 expression in human colonic epithelial cells.

Methods-Intracellular IL-1 content (IL-1 $\alpha$ and IL-1 ) was measured by ELISA in freshly isolated human normal colonocytes. Caspase 1 expression was determined both at the mRNA level using in situ hybridisation and reverse transcription polymerase chain reaction, and at the protein level by immunoblotting experiments using antibodies specific for the proform of caspase 1 and for its cleavage forms.

Results-Low amounts of IL-1及 were found in nearly all preparations (92\%), and IL-1 $\alpha$ was detected in only $45 \%$ of human colonocyte preparations. The normal colonic epithelium strongly expressed caspase 1 , both at the mRNA level and at the protein level in its latent form. In contrast, caspase 1 was not expressed in colon cancer (primary colonic adenocarcinomas and cancer cell lines).

Conclusions-The demonstration that the human colonic epithelial barrier is able to

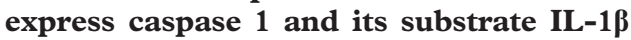
reinforces the concept that, under certain conditions, the epithelium could trigger an inflammatory reaction. In addition, the finding that caspase 1 was downregulated in colonic adenocarcinomas supports the concept that disrupted apoptosis pathways may be involved in tumour formation and/or may confer resistance to treatment. (Gut 1999;45:246-251)
\end{abstract}

Keywords: caspase 1; colonic epithelial cells; colon cancer; interleukin 1 ; interleukin $1 \beta$ converting enzyme

Interleukin (IL) $1 \beta$ converting enzyme (formerly known as ICE and now as caspase 1) is a cysteine protease synthesised as a latent $45 \mathrm{kDa}$ proenzyme that is proteolytically activated by unknown mechanisms into an active form composed of two subunits, one of $20 \mathrm{kDa}$ and one of $10 \mathrm{kDa} .^{12}$ Caspase 1 is responsible for the proteolytic conversion of the $31 \mathrm{kDa}$ inactive cytokine precursor pro-IL- $1 \beta$ into its 17
$\mathrm{kDa}$ active form. ${ }^{1}$ Furthermore, several lines of evidence suggest that caspase 1 , a mammalian homologue of the Caeonorhabditis elegans cell death gene CED-3, is involved in apoptosis. CED-3 and caspase 1 share $28 \%$ sequence identity, and the active site pentapeptide, QACRG, is completely conserved. Overexpression of the murine caspase 1 gene induces apoptosis in Rat-1 cells, which is abrogated by mutations in the catalytic Cys residue..$^{2-4}$

First isolated from monocytic cells, caspase 1 has been recently found in other cell types-for example, keratinocytes, where its main function is to convert pro-IL- $1 \beta$ into mature IL-1 $\beta$ under irritant stress. ${ }^{5}$ It is not known whether other barrier epithelia such as intestinal epithelium are able to express caspase 1 and to produce IL-1 $\beta$.

The objective of this study was to examine the expression of IL- $1 \beta$ and its processing enzyme caspase 1 in the human colonic epithelium by using several complementary methodological approaches. Our results show that caspase 1 is present in $74 \%$ of epithelial preparations, both at the RNA and protein levels. Our demonstration that caspase 1 and IL-1 $\beta$ are both expressed in the intestinal epithelium supports the concept recently put forward that the human intestinal barrier has an immunoregulatory role. ${ }^{6}$ We also show that caspase 1 is present only as a proform in human normal colonocytes. In addition, we show that caspase 1 is downregulated in colonic adenocarcinomas, suggesting that disturbances of the proapoptotic signalling pathways are associated with or causally related to carcinogenesis.

\section{Methods}

ISOLATION OF NORMAL COLONIC EPITHELIAL CELLS

Surgical specimens were obtained from 49 patients undergoing colonic resection for colon adenocarcinoma ( $n=33: 21$ men, 12 women, mean age 71 years (range 54-91)) or for diverticulitis or benign polyps $(n=16$ : eight men, eight women, mean age 61 years (range 29-87)). In all cases, macroscopically normal mucosa, cut out at least at $10 \mathrm{~cm}$ from the lesions, was uninflamed on histological analysis. Histologically normal colonic epithelium was isolated using a non-enzymatic dissociation technique based on the use of the calcium

Abbreviations used in this paper: IL, interleukin; ISH, in situ hybridisation. 
chelating agent EDTA as previously described. ${ }^{7}$ The dissociated cells were collected by centrifugation at low speed, and rinsed in phosphate buffered saline. This technique generated fragmented surface epithelium as well as whole or fragmented crypts, together with isolated colonocytes. Contamination of the cell preparations with non-epithelial cells was assessed using immunohistochemistry with monoclonal antibodies specific for inflammatory/immune cells (anti-CD45, -CD3, -CD20, and -CD14 antibodies; Immunotech, Marseille, France), and for epithelial cells (KL-1; Immunotech), as previously described. ${ }^{7}$ Only preparations devoid of any contaminating macrophages, and containing less than 1\% CD3+ lymphocytes, which were mainly intraepithelial lymphocytes localised within crypts, were studied further.

MEASUREMENT OF INTRACELLULAR IL-1

Intracellular IL-1 was assessed on an aliquot of epithelial cell preparations (about 30 million cells) submitted to three cycles of freeze/thaw in the presence of proteases inhibitors, using specific and sensitive ELISA for IL- $1 \alpha$ and IL-1 $\beta$ (Quantikine IL-1 $\alpha$ or $\beta$ immunoassay kits, R\&D Systems, Oxon, UK), as previously described. $^{8}$ The IL-1 $\beta$ ELISA detects predominantly mature IL- $1 \beta$, and cross reacts with pro-IL-1 $\beta$ (approximately $20 \%$ on a molar basis ${ }^{9}$ ). The results are expressed as pg IL-1 per mg DNA, which was assayed according to Taylor et al. ${ }^{10}$

EXTRACTION OF TOTAL RNA AND REVERSE TRANSCRIPTION POLYMERASE CHAIN REACTION (RT-PCR) ANALYSIS

Total RNA was extracted from the isolated colonic epithelial cells using RNAzol according to the manufacturer's specifications (Bioprobe). RNA was subjected to a DNAse treatment $(2 \mu \mathrm{g} / \mathrm{ml}$, RNAse free DNAse I, Sigma), and $5 \mu \mathrm{g}$ of each sample were reverse transcribed using 200 U Superscript II (Gibco$\mathrm{BRL}$ ) and $0.5 \mu \mathrm{g}$ oligo-dT primer according to standard protocols. A first round of PCR amplification of the resulting cDNA was performed using primers specific for human caspase 1 (sense F1: 5'-ATGGCCGAC AAGGTCCTG-3'; antisense R1: 5'-GGT GGGCATCTGCGCTCT-3') and a second round of amplification with nested primers (sense F2: 5'-GAAGAGAAAGCTGTTTAT CCG-3'; antisense R2: 5'-AATCGAACC TTGCGGAAA-3'). The two pairs of primers were chosen in such a way that the four minor forms of caspase $1 \mathrm{mRNA}$ described by Alnemri and colleagues ${ }^{11}$ could be detected. As a control, $\beta$ actin was amplified in a single round using commercially available oligonucleotides (Clontech, Ozyme, France). Denaturation, annealing, and elongation steps were at $94^{\circ} \mathrm{C}, 60^{\circ} \mathrm{C}$, and $72^{\circ} \mathrm{C}$ respectively, for one minute each, for 25 cycles. The products were then electrophoresed in $1 \%$ agarose gel with a DNA weight marker ( $\phi$ X174-HaeIII). The expected size of the products were $1102 \mathrm{bp}$ for the major form of caspase 1 mRNA after nested PCR and 838 bp for $\beta$ actin. The specificity of the PCR products obtained with caspase 1 primers was verified by Southern blot hybridisation using a digoxigenin labelled caspase 1 DNA probe, generated from a full length cDNA (kind gift of Dr Gillis, Immunex). Detection of Southern hybridisation was performed using a digoxigenin detection kit (Boehringer Mannheim).

\section{IN SITU HYBRIDISATION}

Sense and antisense single strand DNA digoxigenin labelled probes specific for caspase 1 were obtained by minor modifications of the protocol of Hannon et al. ${ }^{12}$ Briefly, two double strand DNA digoxigenin labelled probes were synthesised by PCR using one phosphorylated primer (either sense primer F2 or antisense R2) and DIG- ${ }^{11}$ dUTP nucleotide (BoehringerMannheim). The two amplification products were then subjected to a $\lambda$ exonuclease digestion ( $3 \mathrm{U} / \mu \mathrm{l}$; Life Technologies), leading to 1102 bp single strand DNA probes, which were subjected to alkaline hydrolysis to generate smaller fragments.

In situ hybridisation (ISH) was performed on $5 \mu \mathrm{m}$ cryostat sections obtained from human colonic mucosa, placed on silanised slides, fixed for 15 minutes with $4 \%$ paraformaldehyde, and rinsed with phosphate buffered saline. The sections were then permeabilised with $0.2 \mathrm{~N} \mathrm{HCl}$ for 20 minutes, rinsed in distilled water, and then in $2 \times$ saline sodium citrate for 10 minutes, postfixed in $4 \%$ paraformaldehyde for five minutes, and washed in phosphate buffered saline before hybridisation, which was performed according to Hannon et $a{ }^{12}$ Colorimetric detection of digoxigenin labelled probe was then performed using antidigoxigenin-alkaline phosphatase and substrate solution (NBT/BCIP supplemented with levamisole), according to the manufacter's instructions (Boehringer Mannheim). Nuclei were counterstained with malachite green (Sigma), and sections mounted in glycergel (Dako). The following controls were performed for each case studied: labelling with a caspase 1-digoxigenin labelled sense probe; omission of the caspase 1 antisense probe; and checking the integrity of degradation of $\mathrm{mRNA}$ with a digoxigenin labelled $\mathrm{d}(\mathrm{T})_{30}$ oligonucleotide (R\&D Systems).

WESTERN IMMUNOBLOT ANALYSIS

Pellets of isolated colonic epithelial cells were lysed for 30 minutes at $4^{\circ} \mathrm{C}$ in buffer containing $0.5 \%$ Triton X-100, $20 \mathrm{mM}$ Tris $\mathrm{HCl} \mathrm{pH} \mathrm{7.5,} 1 \mathrm{mM}$ EDTA, $10 \mu \mathrm{g} / \mathrm{ml}$ aprotinin, and leupeptin (Sigma). Lysates were centrifuged for 10 minutes at $10000 \mathrm{rpm}$. The protein concentration was determined using a Bradford assay (Biorad). A $10 \mu$ aliquot of supernatant $(100 \mu \mathrm{g}$ protein) was mixed with $2 \times$ sodium dodecyl sulphate polyacrylamide gel electrophoresis (SDS-PAGE) sample buffer, boiled for five minutes, and run on $10 \%$ SDS-polyacrylamide. Proteins were electrotransferred onto nitrocellulose membranes (Schleicher and Schuell, Ceralabo) using a transblot apparatus (Biorad). The membranes were blocked for two hours with $1 \%$ blocking 


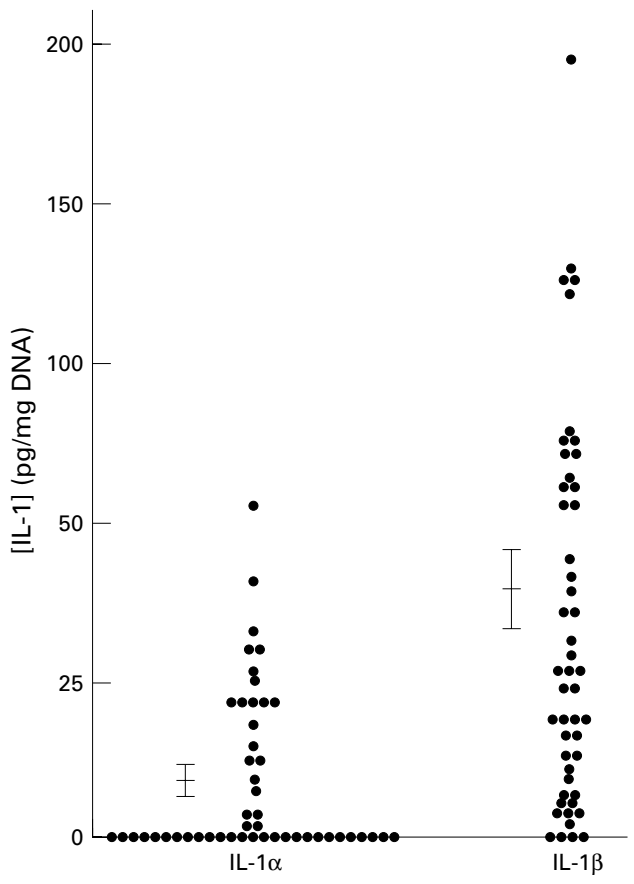

Figure 1 Intracellular IL-1 concentrations in isolated human colonocytes $(n=49)$. Means are shown by horizontal bars and standard errors by vertical bars.

reagent (Boehringer Mannheim), and probed with the following primary antibodies for one hour: (1) a rabbit polyclonal antibody raised against an epitope corresponding to the amino acids 2-20 mapping at the aminoterminus of the caspase 1 precursor form, and which does not cross react with ICE-like caspases (anti-
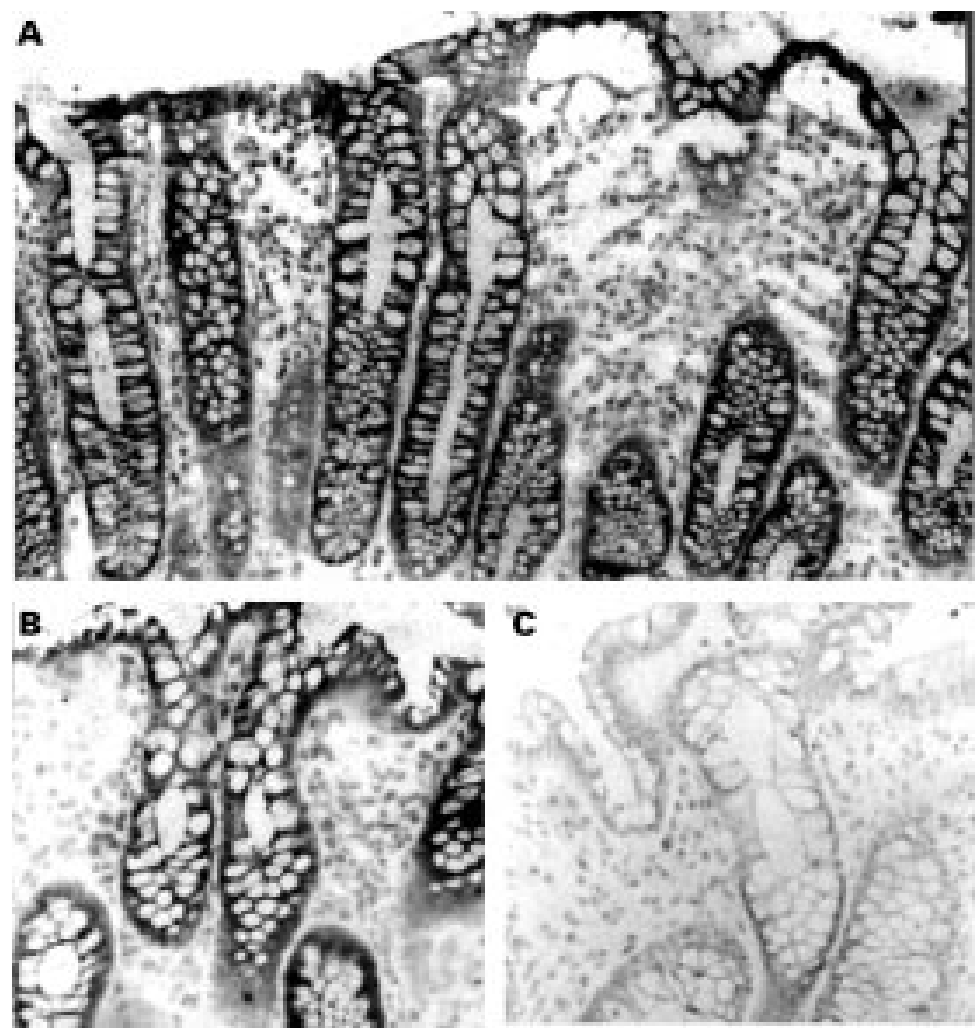

Figure 2 Detection of caspase 1 by in situ hybridisation in the normal human colonic mucosa. Colonocytes strongly expressed caspase $1 \mathrm{mRNA}(A, B)$. Control section hybridised with a caspase 1 sense probe revealed no specific signal $(C)$. Original magnification $\times 350$ $(A), \times 700(B, C)$.
ICE, ref. SC-622, Santa Cruz, Tebu, France); and (2) a rabbit polyclonal antibody raised against an epitope corresponding to amino acids 385-404 mapping at the carboxyterminus of caspase 1 (anti-ICE p10, ref. SC-515, Santa Cruz). After washing, the membranes were further incubated for 30 minutes with a horseradish peroxidase conjugated goat antirabbit antibody (Boehringer Mannheim). After washing, the immunoreactive proteins were detected on films using an enhanced chemiluminescent substrate according to the manufacturer's instructions (Boehringer Mannheim, France). The specificity of the signal obtained was checked after preabsorbing the anti-ICE antibody with the corresponding blocking peptide.

\section{Results}

IL-1 PRODUCTION BY HUMAN COLONOCYTES Intracellular IL-1 (IL-1 $\alpha$ and IL-1 $\beta$ ) content was measured by ELISA in 49 preparations of isolated human colonocytes. Figure 1 shows that measurable amounts of IL-1 $\beta$ were found in 45 preparations (92\%), and of IL- $1 \alpha$ in 22 preparations $(45 \%)$. In all but two preparations, the IL- $1 \beta$ level was higher than the IL- $1 \alpha$ level. Interestingly, IL-1 expression (both IL- $1 \alpha$ and IL-1 $\beta$ ) was undetectable in only four preparations.

CASPASE 1 EXPRESSION IN HUMAN COLONOCYTES Caspase 1 expression by human colonocytes was examined and characterised: (1) at the mRNA level, using ISH and RT-PCR on mRNA extracted from isolated colonocytes; and (2) at the protein level by immunoblotting experiments using antibodies specific for the proform of caspase 1 or for its cleavage forms.

In situ hybridisation was performed on cryostat sections of 19 specimens of histologically normal colon using a digoxigenin labelled caspase 1 antisense probe. Fourteen of 19 samples $(74 \%)$ showed positive labelling localised in the epithelium. A representative ISH experiment (fig 2A,B) shows strong epithelial labelling of both the surface and the colonic crypts, which was mainly cytoplasmic. The specificity of the labelling with the antisense probe was tested using two types of controls: (1) by using a digoxigenin labelled sense probe; and (2) by

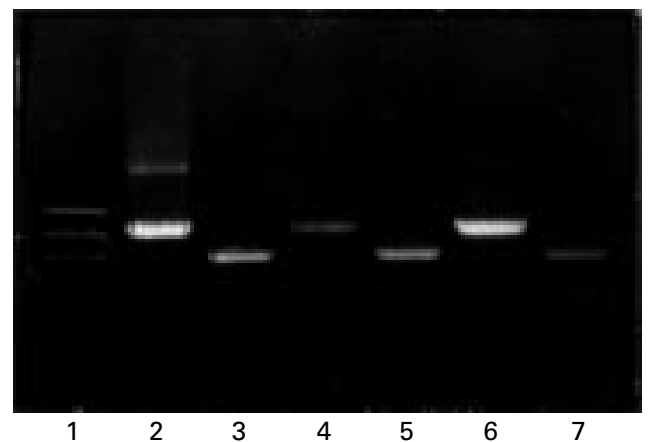

Figure 3 RT-PCR analysis of caspase 1 expression in human normal isolated colonocytes. Lane 1 shows DNA weight marker $\phi X 174-H a e I I I$. Lanes 2, 4, 6 show caspase 1 amplification products from three different colonocyte preparations; lanes $3,5,7$ show $\beta$ actin amplification products from the same preparations. 

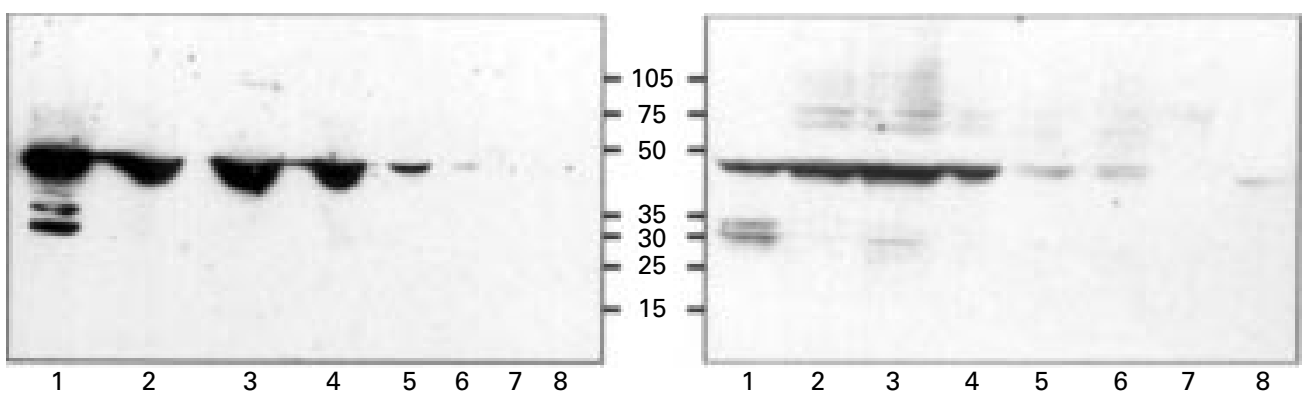

Figure 4 Caspase 1 expression in human normal isolated colonocytes at the protein level. Eight different cell lysates were subjected to immunoblotting experiments. They were run on SDS-PAGE gels, blotted, and probed with either an anticaspase 1 p45 antibody (left) or with an anticaspase 1 p10 antibody (right). Numbers between the two panels indicate molecular size of standards in $k D a$.

omitting the antisense probe in the hybridisation procedure. In these controls, the labelling was abolished (fig 2C). Finally, the absence of labelling in five cases was not accounted for by RNA degradation, as strong labelling was observed using an oligo-dT probe (data not shown).

RT-PCR experiments were performed to characterise the isoform of mRNA coding for caspase 1 in human isolated colonocytes. As shown in fig 3, a unique DNA product of 1102 bp was detected by ethidium bromide staining and was subsequently identified as caspase 1 by Southern blot hybridisation using the full length caspase $1 \mathrm{cDNA}$ as a probe (data not shown). As oligonucleotide primers were chosen in such a way that they could generate amplification products encompassing all the known isoforms of mRNA coding for caspase 1 , these findings show that only one isoform of caspase $1 \mathrm{mRNA}$ is expressed in human colonocytes.

To determine whether caspase 1 protein was expressed in human normal colonocytes, immunoblotting experiments were performed on lysates of eight preparations of isolated colonocytes. The cell lysates were run on SDS-PAGE gels, and transferred onto nitrocellulose filters which were probed with either an anti-p45 antibody specific for caspase $1 \mathrm{p} 45$ proform or with an anti-p10 antibody which recognises both the $\mathrm{p} 45$ proform and the p10 cleavage form. In six of the eight preparations, both antibodies labelled a single major band at the $45 \mathrm{kDa}$ position (fig 4). The anti-p10 antibody failed to show a band at the $10 \mathrm{kDa}$ position. Confirmation of the specificity of the labelling came from preabsorbing the antibodies with their corresponding blocking peptides, which resulted in full abolition of the labelling (not shown).

There was an excellent correlation between the results of the two techniques used for the detection of caspase 1 (immunoblotting and ISH). In some preparations ICE expression and IL- $1 \beta$ levels were compared; the presence of caspase 1 was always associated with detectable levels of IL-1 $\beta$ in cell lysates. In other words, when IL- $1 \beta$ was undetectable, there was no expression of caspase 1. Unexpectedly, in three cases, measurable levels of IL- $1 \beta$ were found in the absence of detectable caspase 1 .
CASPASE 1 EXPRESSION IN HUMAN COLONIC ADENOCARCINOMAS

Our findings prompted us to examine in parallel the expression of caspase 1 in human colonic adenocarcinomas using ISH. In 10 $(70 \%)$ of the 14 samples studied, cancer cells did not express caspase $1 \mathrm{mRNA}$. By contrast, in all the cases studied the corresponding normal epithelium was found to express caspase 1 mRNA (fig 5A), both in the immediate vicinity of the tumour and at some distance $(10 \mathrm{~cm}$ at
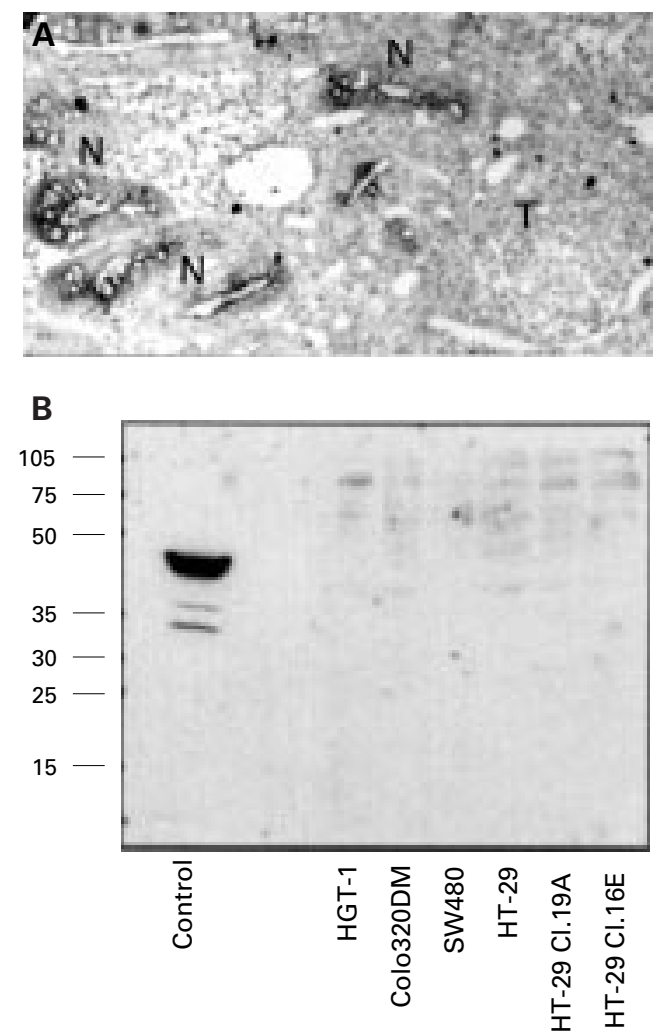

Figure 5 Downregulation of caspase 1 expression in colon cancer. (A) In situ hybridisation performed on cryostat sections of a primary colon adenocarcinoma shows that tumour cells (T) do not express caspase $1 \mathrm{mRNA}$, whereas normal crypts $(N)$ in the vicinity of the tumour are labelled with the antisense caspase 1 probe (original magnification $\times 350)$. (B) Immunoblot analysis of caspase 1 protein expression using an anti-p45 antibody in several digestive cancer cell lines: the gastric cell line HGT-1 and the colonic cell lines Colo320DM, SW480, HT-29 and its clonal derivatives Cl.19A and Cl.16E. The control lane is a lysate from an ulcerative colitis mucosa, showing strong expression of the $45 \mathrm{kDa}$ proform. Numbers on the left indicate molecular size of standards in $k D a$. 
least from the tumour). The absence of caspase 1 expression in cancer cells could not be accounted for by RNA degradation in these cells as an oligo-dT probe showed strong labelling. Finally, of the four positive adenocarcinomas, three presented homogeneous staining whereas one was heterogeneously labelled.

To extend our findings of the downregulation of caspase 1 expression in cancer cells, we evaluated the expression of caspase 1 at the protein level in the following human digestive cancer cell lines: the gastric cell line HGT-1, the colonic cell lines Colo320DM and SW480, and the parental undifferentiated HT-29 cell line and its stably differentiated clonal derivatives HT-29 Cl.16E and HT-29 Cl.19A. Lysates of confluent cell monolayers were run on SDS-PAGE gels, and transferred on nitrocellulose filters, which were probed with either anti-p45 or anti-p10 antibodies. Using these antibodies, we failed to show any $\mathrm{p} 45$ proform or any $\mathrm{p} 10$ cleavage form in each cell line tested (fig 5B).

\section{Discussion}

The two main findings of this study are: (1) the human colonic epithelial barrier strongly expresses the precursor form of caspase 1 ; and (2) caspase 1 expression is downregulated in human colonic cancer.

Caspase 1 was found to be an abundant protein, easily detectable both at the protein level by immunoblotting experiments, and at the mRNA level using ISH. Using appropriate antibodies we only detected the $\mathrm{p} 45$ proform of caspase 1, a result that can be interpreted in two ways with regard to the potential activity of this protein. Our data can be explained in the light of findings showing that caspase 1 is present in blood monocytes as a large pool of intracytoplasmic precursor, and that very limited amounts of mature caspase 1 are present, but nevertheless sufficient to allow efficient IL- $\beta$ cleavage. ${ }^{13}$ This cleaved form of caspase 1 remains undetectable using the usual analytical tools - immunoblotting or immunoprecipitation. ${ }^{13}{ }^{14}$ In contrast, the recent demonstration that normal colonic macrophages restrict the expression of both caspase 1 and IL- $1 \beta$ to their inactive precursor forms makes it conceptually possible that in the same way normal human colonocytes fail to activate caspase 1 and as a consequence are unable to process the precursor form of IL- $1 \beta .^{9}$

To gain more insight into this issue, we measured the intracellular amounts of both IL- $1 \alpha$ and IL- $1 \beta$. Measurable amounts of IL- 1 , mainly IL-1 $\beta$, were detected in epithelial cell lysates using a very sensitive ELISA technique, in keeping with our demonstration of the IL-1 $\beta$ processing machinery in human colonocytes. Very low levels of intracellular IL-1 were found, a result in accord with previous findings. ${ }^{15}$ These very low levels of IL- $1 \beta$ precluded any mechanistic study based on the immunoblotting analysis typified by McAlindon et al, who deciphered IL-1 $\beta$ processing and extracellular release from human lamina propria macrophages. ${ }^{9}$ Our findings, together with data from the literature, ${ }^{91314}$ strongly argue that tight post-translational control of caspase 1 maturation could represent a specific step in the regulation of caspase 1 enzymatic activity in the human intestinal epithelial barrier.

In addition, our demonstration that IL-1 is expressed by the intestinal epithelial barrier along with its processing machinery (caspase 1) is in keeping with the concept recently put forward that the intestinal epithelium subjected to an irritant stress has a proinflammatory role. ${ }^{6}{ }^{16-18}$ Indeed, Radema et al have shown, using ISH in a model of experimental colitis, that enterocytes synthesise IL- $1 \beta$ mRNA, and this IL- $1 \beta$ of epithelial origin seems to be an early feature of experimental colitis, preceding tissue damage. ${ }^{18}$

In addition to being an IL-1 $\beta$ processing enzyme, IL- $1 \beta$ converting enzyme is also the founder of a family of proapoptotic cysteine proteases, the so called caspases. That caspase 1 is an important regulator of epithelial cell apoptosis has been exemplified by the work of Boudreau and colleagues ${ }^{19}$ who showed that involution of mammary epithelial cells is associated with caspase 1 activation, a process blocked by crmA, a specific inhibitor of caspase 1. However, this study does not provide a conceptual framework for explaining the role of caspase 1 in intestinal epithelium as involutive processes are strictly restricted to specific tissues which do not include the gastrointestinal tract in the adult. A more plausible scenario is based on recent work by Tamura et al. ${ }^{20}$ Using mature $\mathrm{T}$ lymphocytes as a model system, these authors showed that concanavalin A activation leads to the expression of caspase 1 in its latent form which in turn is able, through its cleavage, to translate a genotoxic stress into a proapoptotic signalling. In the future, primary cultures of caspase 1 expressing colonocytes will provide the means of testing the hypothesis that DNA damaging agents are responsible for colonocyte apoptosis through the cleavage of latent caspase 1 .

Our demonstration of the downregulation of caspase 1 in colon cancer and several cancer cell lines has several implications in cancer biology. Firstly, it accounts for the finding that IL-1 expression in several intestinal cell lines including HT29-Cl.16E is restricted to IL- $1 \alpha^{821}$; this could reflect the inability of colonic cancer cells to elicit an adequate proinflammatory response under the same conditions as those leading to the production of IL-1 $\beta$ in normal colonocytes. Secondly, our findings are in accord with the concept that disrupted apoptosis pathways may be involved in tumour formation and/or may confer resistance to treatment approaches. ${ }^{22}$ In fact, recent work based on the use of specific caspase inhibitors and antisense approaches has shown that apoptosis induced in tumour cells by chemotherapeutic drugs requires the activation of caspase 1 and caspase $3 .^{23}$ These findings, together with our demonstration of caspase 1 downregulation in colon cancer, could explain the resistance of colon cancer to a variety of anticancer drugs. 
We gratefully thank Mrs M Robard and Mrs S Parois for skilful technical assistance. This work was supported in part by the Comité Départemental de Loire Atlantique de la Ligue Nationale contre le Cancer and by the Conseil Régional des Pays de la Loire.

1 Thornberry NA, Bull HG, Calaycay JR, et al. A novel heterodimeric cysteine protease is required for interleukin-1 $\beta$ processing in monocytes. Nature 1992;356:768-74.

2 Nicholson DM, Thornberry NA. Caspases: killer proteases. Trends Biochem Sci 1997;22:299-306.

3 Kumar S. ICE-like proteases in apoptosis. Trends Biochem Sci 1995;20:198-202.

4 Cohen GM. Caspases. The executioners of apoptosis. Biochem $\mathcal{F}$ 1997;326:1-16.

5 Zepter K, Haffner A, Soohoo LF, et al. Induction of biologically active IL-1 beta-converting enzyme and mature IL-1 beta in human keratinocytes by inflammatory and immunologic stimuli. F Immunol 1997;159:6203-8.

6 Kagnoff MF, Eckmann L, Yang S-K, et al . Intestinal epithelial cells: an integral component of the mucosal immune system. In: Kagnoff MF, Kiyono $\mathrm{H}$, eds. Essentials of system. In: Kagnoff MF, Kiyono H, eds. Essentials of
mucosal immunology. New York: Academic Press, 1996:6371 .

7 Branka J-E, Vallette G, Jarry A, et al. Early functional effects of Clostridium difficile toxin A on human colonocytes. of Clostridium difficile toxin A on

8 Vallette G, Jarry A, Lemarre P, et al. NO-dependent and NO-independent IL-1 production by a human colonic epithelial cell line under inflammatory stress. Br F Pharmaco 1997;121:187-92

9 McAlindon ME, Hawkey CJ, Mahida YR. Expression of interleukin $1 \beta$ and interleukin $1 \beta$ converting enzyme by intestinal macrophages in health and inflammatory bowel disease. Gut 1998;42:214-19.

10 Taylor CM, Blanchard B, Zava DT. A simple method to determine whole cell uptake of radiolabelled oestrogen and progesterone and their subcellular localization in breast cancer cell lines in monolayer cultures. F Steroid Biochem 1984;20:1083-8.

11 Alnemri ES, Fernandes-Alnemri T, Litwack G. Cloning and expression of four novel isoforms of human interleukin-1 $\beta$ converting enzyme with different apoptotic activities. $\mathcal{F}$ Biol Chem 1995;9:4312-17.

12 Hannon K, Johnstone E, Craft LS, et al. Synthesis of PCRderived, single-stranded DNA probes suitable for in situ hybridization. Anal Biochem 1993;212:421-7.

13 Miossec C, Decoen M-C, Durand L, et al. Use of monoclonal antibodies to study interleukin- $1 \beta$ converting enzyme expression: only precursor forms are detected in enzyme expression: only precursor forms are detected in interleukin-1

14 Ayala JM, Yamin T-T, Egger LA, et al. IL-1 $\beta$ converting enzyme is present in monocytic cells as an inative $45-\mathrm{KDa}$ precursor. F Immunol 1994;153:2592-9.

15 Casini-Raggi V, Kam L, Chong YJT, et al. Mucosal imbalance of IL-1 and IL-1 receptor antagonist in inflammatory bowel disease. A novel mechanism of chronic intestinal inflammation. F Immunol 1995;154:2434-40.

16 Lammers KM, Jansen J, Bijlsma PB, et al. Polarised interleukin 8 secretion by HT29-Cl.19A cells. Gut 1994;35:338-42.

17 Hoang P, Crotty B, Dalton HR, et al. Epithelial cells bearing class II molecules stimulate allogeneic human colonic intraepithelial cells. Gut 1992;33:1089-93.

18 Radema SA, Van Deventer SJ, Cerami A. Interleukin 1 beta is expressed predominantly by enterocytes in experimental colitis. Gastroenterology 1991;100:1180-6.

19 Boudreau N, Sympson CJ, Werb Z, et al. Suppression of ICE and apoptosis in mammary epithelial cells by extracellular matrix. Science 1995;267:891-3.

20 Tamura T, Ishihara M, Lamphier MS, et al. An IRF-1dependent pathway of DNA damage-induced apoptosis in mitogen-activated T lymphocytes. Nature 1995;376:596-9.

21 Stadnyk AW, Sisson GR, Waterhouse CCM. IL-1 $\alpha$ is constitutively expressed in the rat intestinal epithelial cell line IEC-6. Exp Cell Res 1995;220:298-303.

22 Thompson CB. Apoptosis in the pathogenesis and treatment of disease. Science 1995;267:1456-62.

23 Los M, Herr I, Friesen C, et al. Cross-resistance of CD95and drug-induced apoptosis as a consequence of deficient activation of caspases (ICE/Ced-3 proteases). Blood 1997;90:3118-29. 